\title{
FORMAÇÃO OPERÁRIA: ARTE DE LIGAR POLÍTICA E CULTURA
}

\author{
Kátia Rodrigues Paranhos*
}

Ah, homens de pensamento Não sabereis nunca o quanto

Aquele humilde operário Soube naquele momento! (...) além do que sabia

- Exercer a profissão O operário adquiriu A dimensão da poesia.

(Vinicius de Morais, O operário em construção)

RESUMO: Este artigo constitui uma tentativa de resgate e reconstrução das propostas e iniciativas de formação sindical e/ou operária promovidas por diferentes entidades de trabalhadores. Neste sentido, desenvolve um balanço histórico que busca mostrar que as práticas de formação não representam uma novidade, fazendo parte da história dos trabalhadores e de suas organizaçóes. O texto é orientado numa perspectiva de análise que procura realçar a importância das atividades de formação na experiência do movimento operário nos séculos passados e no momento atual.

Palavras-chave: Formação operária. Iniciativas e propostas de formação. Estudo e cultura.

WORKER'S EDUCATION: THE ART OF JOINING ART AND CULTURE

ABSTRACT: This article constitutes an attempt to redeem and reconstruct the proposals and initiatives of trade union worker's and/ or worker's training promoted by different worker's organizations. In this way it develops a historical oscillation that wants to show that the practices on formation do not represent a novelty, but are part

* Professora do Instituto de História da Universidade Federal de Uberlândia (UFU). E-mail: akparanhos@triang.com.br 
of the workers history and their organizations. The text is oriented in an analytical perspective whose aim is to highlight the importance of the educational activities based on the worker's experience during the movement of the past centuries and at the current moment.

Key words: Worker's training. Educational proposals and initiatives.

Study and culture.

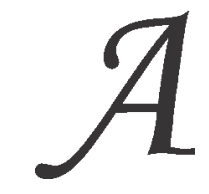

história da formação do trabalhador no capitalismo é a história de sua desqualificação, fato esse apontado por Marx e que permanece encoberto nas obras de economistas contemporâneos seus, cujo discurso é o da qualificação como resultado do desenvolvimento do capitalismo. Para Marx, o modo de produção capitalista é caracterizado, entre outros aspectos, pela exploração do trabalho humano e pela sua alienação.

Já nos "Manuscritos econômicos e filosóficos" (Marx, 1979) aparece o conceito de "trabalho" e o papel que ele desempenha na construção do homem e da sociedade. O trabalho é visto como a "essência do homem" e, ao mesmo tempo, como "trabalho alienado". ${ }^{1}$ Ao verificar que o trabalho concreto é o trabalho alienado, Marx conclui que a essência do homem está divorciada de sua existência, e, embora tenha estudado particularmente a sociedade burguesa, ele demonstra que historicamente, dada a debilidade do homem diante da natureza, nunca houve trabalho que não fosse alienação. Propõe, então, que a essência humana seja concebida como trabalho criador, em que o homem se reconheça em seus produtos, em sua própria atividade e nas relações que estabelece com outros homens - o que só será possível por ocasião da superação do modo de produçãao capitalista.

É evidente que Marx realça a importância do trabalho para o homem, mas também salienta o potencial cultural humano tanto nas relações sociais, que lhe são inerentes, como na própria execução da tarefa. No entanto, quando menciona a ação como formação, não a limita exclusivamente à prática profissional. Trata-se também, e principalmente, da ação militante e revolucionária à luz do conhecimento do socialismo científico.

O estudo, aos olhos de Marx, uma vez que está presente na formação dos trabalhadores, não pode ser concebido, no regime capitalista, como uma maneira de formar o homem completo com base numa instrução que se possa chamar integral. Para ele - em sua obra clássica, vol- 
tada para o século XIX, O capital -, "na sociedade capitalista, conseguese tempo livre para uma classe, transformando a vida inteira das massas em tempo de trabalho". O que efetivamente inviabiliza condições de vida mais ricas para o trabalhador, em termos de "atividade livre, espiritual e social (...)" (Marx, 1982, v. 2, p. 606-607). ${ }^{2}$ Marx e Engels apostam em uma "nova sociedade" em que o trabalhador administre, como the aprouver, o "tempo livre".

Mas, nas condições concretas do capitalismo, o estudo em escolas de formação profissional, por exemplo, não é indiferente aos interesses do proletariado, incapaz de superar sua condição de dominação sem a reapropriação do saber sobre o trabalho, que até agora era incorporado ao capital e convertido em força de dominação. Por isso, a aquisição do saber sobre o trabalho capitalista é um passo importante rumo à sua superação. A conquista do poder político pela classe trabalhadora trará a adoção do ensino tecnológico, teórico e prático para os trabalhadores, e esse saber se constitui no fermento de transformação da "velha divisão do trabalho" (Marx, 1982, v. 1, p. 559). ${ }^{3}$ A fábrica capitalista é lugar de qualificação e de desqualificação. $\mathrm{O}$ indivíduo educa-se, faz-se homem, na produção e nas relações de produção, por meio de um processo contraditório em que estão sempre presentes, e em confronto, momentos de educação e de deseducação e, portanto, de humanização e de desumanização. A pedagogia capitalista, ao mesmo tempo em que objetiva a educação do trabalhador como força de trabalho submetida à dominação exercida pelo capital, educa-o também para enfrentar a dominação.

Se no pensamento marxista a fábrica é vista como um lugar de sofrimento e de cansaço extremos, ao mesmo tempo, contraditoriamente, esse lugar de desqualificação é também o da qualificação. Já que o saber fabril instrumentaliza o trabalhador para a luta, para a transformação da divisão do trabalho e, conseqüentemente, para a mudança da sociedade.

Essa contradição está presente também nos escritos sobre os sindicatos e o sindicalismo. Marx e Engels apontam os limites do sindicalismo (e suas posturas complacentes diante do salariato) e o reconhecimento, simultâneo, do valor da luta dos sindicatos como "centros de organização da classe operária". Richard Hyman, no verbete "sindicatos e sindicalismo", em Dicionário do pensamento marxista (Bottomore, 1988), constata a existência dessa tensão, entre valor e limites dos sindicatos e do sindicalismo, no pensamento de Marx: 
Acima de tudo, a experiência sindical ampliava a autoconfiança dos trabalhadores e a sua consciência de classe: como "escolas de guerra, os sindicatos não têm competidores", diz Engels em A condição da classe trabalhadora na Inglaterra. (...). Marx e Engels, anos depois, ainda sustentavam que o sindicato era "a verdadeira organização de classe do proletariado", criticando o programa de Gotha por omitir qualquer análise da questão (...). Há uma tensão importante na experiência e nos escritos de Marx e Engels, a partir da década de 1850, entre a concepção de que os sindicatos eram instituiçóes que se haviam tornado legítimas e complacentes e a perspectiva de que dispunham de um potencial e de uma prática mais radicais. Surpreendentemente, essa tensão não foi nunca enfrentada de maneira sistemática ou teórica: em $O$ capital há apenas referências de passagem aos sindicatos, embora as lutas políticas pela limitação do dia de trabalho sejam discutidas com alguma minúcia. (Bottomore, 1988, p. 335)

Marx ressaltou que os sindicatos funcionariam como "centros de organização da classe operária", mesmo que não tivessem inicialmente essa consciência. Desse modo, esses loci de organização da classe operária superariam a "forma sindicato" e teriam o potencial de transformarse em força organizada para acabar com a ordem burguesa. Enfim, teriam condições de transformar-se em organização de massa do proletariado inglês, com base num programa que fosse abolir o sistema de trabalho assalariado e a dominação do capital.

Mesmo reconhecendo o problema da formação operária em uma sociedade de classes, não apenas Marx e Engels, mas historicamente os socialistas, comunistas e anarquistas envolvidos com o movimento operário entendem a importância da fábrica e do sindicato para a instrução dos trabalhadores, como enfatizam também "outros canais" para a formação operária: o estudo em escolas para trabalhadores e a dimensão educativa da cultura.

\section{Experiências de formação}

$\mathrm{Na}$ Europa, as atividades de formação sindical e/ou operária desenvolveram-se já a partir do final do século XVIII. Os ingleses, por exemplo, criaram escolas para adultos - a de Nottingham foi inaugurada em 1798 - com a preocupação prática de ensinar as pessoas a ler e de ensinar-lhes, depois, o que elas teriam necessidade de saber para a própria profissão e promoção. Assim, tanto na Inglaterra quanto na França, o movimento operário nascente se preocupava com a sua for- 
mação por intermédio da instrução dos trabalhadores adultos, ou seja, com objetivo técnico-profissional. $\mathrm{Na}$ verdade, atravessa-se um período de entusiasmo pelos cursos técnicos noturnos oferecidos pelas escolas e associações de engenheiros (David, 1974, p. 267-306)

A partir da metade do século XIX, o movimento de educação divide-se em duas correntes. A primeira, de ideologia socialista, persevera na sua meta de educação do povo, o que resultará no movimento chamado "universités populaires" (universidades populares), iniciado nos primeiros anos do século XX. Em 1902, de acordo com Benigno Caceres, "havia 47 universidades populares em Paris, 48 nos subúrbios e umas 50 na província, como as de Brest (...) e de Rennes, nas quais se operou pouco a pouco uma íntima fusão entre estudantes e operários" (Caceres, apud Mucchielli, 1980, p. 11).

A segunda corrente desenvolveu-se separadamente e centralizouse nas chamadas necessidades da formação de adultos e da promoção profissional. E tanto os sindicatos como os governos tentaram organizar instituições de formação.

$\mathrm{Na}$ Inglaterra, em homenagem ao apóstolo da educação dos trabalhadores, John Ruskin (1819-1900), foi fundado em Oxford, em 1899, o "Ruskin College" da Universidade de Oxford. Essa instituição estava voltada para a idéia de democratizar a cultura e promover, por meio da educação dos trabalhadores adultos, um horizonte social mais eqüitativo. Mas não se deve ignorar que o vínculo com o conhecimento científico no Ruskin College estava orientado para a melhor preparação técnica do trabalhador. No espírito radicalizado do liberalismo inglês, não era o socialismo que traria a aliança entre o trabalho e a ciência, mas uma digna relação do produtor com a matéria, por uma instrumentalização técnica mais qualificada que permitisse uma transformação harmoniosa. ${ }^{4}$

Verifica-se então, durante a década de 1910, a bem-sucedida experiência dos dissidentes "marxianos" do Ruskin College, que, iniciada no Central Labour College de Londres e na sua íntima aliada, a Plebs League, expande-se para outras regiōes operárias - sobretudo Escócia, sul de Gales e Lancashine - com o objetivo da educação voltada para o socialismo (ver Holford, op. cit., p. 25-28).

$\mathrm{Na}$ França, desde 1865 foram organizados cursos noturnos. Em 1919, a Lei Astier determina que todos os jovens em fase de aprendizagem nas empresas devem receber cursos profissionais de ensino téc- 
nico. Em abril de 1928, tem-se a criação de uma escola de aperfeiçoamento em administração de empresas. Em 1930, é fundado o primeiro instituto de promoção e de formação de adultos, o "Centre de Perfectionnement dans l'Administration des Affaires". Em 1936, o governo organiza a promoção social - tanto profissional como sindical e operária, por meio dos "Collèges du Travail" (Colégios de Trabalho) e das "Ecoles Normales Ouvrières" (Escolas Normais Operárias). Em 1946, o Estado cria uma Direção-Geral da Educação Popular e dos Esportes. Em abril de 1948, são organizados os Cursos de Aperfeiçoamento para a Promoção do Trabalho (Cf. Mucchielli, op. cit., p. 11-13).

Assim, a preocupação com a educação permanente e com a difusão da cultura vem tanto das university extensions inglesas quanto das universidades populares dinamarquesas, criadas na metade do século XIX e que se desenvolveram também em outros países entre o fim do século XIX e o início do século XX.

Historicamente, é necessário assinalar como o movimento operário, desde as fases iniciais, é tributário tanto de lutas econômicas e políticas como culturais; por exemplo, as experiências da Alemanha e Áustria, que podem ser destacadas como tradições em matéria de "cultura para operários". Desde 1860, os trabalhadores desses países encontraram um lugar (nas "Arbeiterbildungverein") de esclarecimento político, ideológico, educativo e cultural. E interessante lembrar que a vida da social-democracia havia sido incubada e preservada nas fórmulas dos clubes culturais operários, único modo de manifestação permitido até as reformas bismarckianas. Entretanto, as sucessivas interdiçôes à vida gremial e política do proletariado nesses países significaram duros golpes nas experiências de "cultura operária", incluídas aí as instituições educativas para crianças, as Frei Schule, que em muitos casos tiveram uma vida raquítica, mas que constituíram, em alguns momentos, um movimento de algum significado nas sociedades alemã e austríaca.

$\mathrm{Na}$ última década do século XIX e nas primeiras décadas do século XX, a social-democracia desenvolvera um vasto número de experiências culturais entre os trabalhadores, desde formas muito estruturadas até os indispensáveis programas difusores de saberes científicos, arte, conhecimentos literários e ilustração política, assim como organizara a primeira escola do Partido Social Democrata Alemão. Foram professores da escola do partido alemão intelectuais marxistas e lideranças operárias, como Rosa Luxemburgo, August Bebel e Franz Mehring. ${ }^{5}$ 
Os militantes operários (assim como os próprios governos) atribuíam uma importância fundamental à educação dos trabalhadores. Dessa forma, dirigentes, ativistas sindicais, trabalhadores mais qualificados e artesãos, geralmente por meios autodidáticos, tentavam ampliar seus conhecimentos e transmiti-los aos demais. Procurando suprir as deficiências do sistema escolar da época, empenhavam-se em obter um bom preparo teórico, a fim de oferecer uma contrapartida operária ao saber aristocrático, burguês ou religioso. A preocupação educacional tinha também finalidades políticas, como a criação de centros de discussão que serviam de foco de aglutinação e politização dos trabalhadores.

Referindo-se à educação operária na Inglaterra, escreve E.P. Thompson $(1987$, p. 303-304 e p. 312):

A consciência articulada do autodidata era sobretudo uma consciência política. (...) a primeira metade do século 19 , quando a educação formal de grande parte do povo se resumia a ler, escrever e contar, não foi absolutamente um período de atrofia intelectual. As vilas, e até as aldeias, ressoavam com a energia dos autodidatas. (...) os diaristas, artesãos, lojistas, escreventes e mestres-escolas punham-se a aprender por conta própria, individualmente ou em grupo. E os livros ou instrutores, muitas vezes, eram os que contavam com a aprovação da opinião reformadora. Um sapateiro, que aprendera a ler pelo Antigo Testamento, ia se aperfeiçoar com a Idade da razão; um mestre-escola, cuja instrução não o levara muito além de meritórias homilias religiosas, tentaria Voltaire, Gibbon, Ricardo; aqui e ali, líderes radicais locais, tecelães, livreiros, alfaiates reuniriam pilhas de periódicos radicais e aprenderiam a usar as publicaçóes oficiais do Parlamento; diaristas analfabetos nem por isso deixavam de ir, todas as semanas, a um bar onde lia-se em voz alta e discutia-se o editorial de Cobbett.

Assim, a partir de sua experiência própria e com o recurso à sua instrução errante e arduamente obtida, os trabalhadores formaram um quadro fundamentalmente político da organização da sociedade. (...)

A despeito da repressão a partir de 1819, a tradição de manter (...) salas de notícias (às vezes associadas à loja de um livreiro radical) continuou pelos anos de 1820. Em Londres, depois da guerra, houve uma proliferação de cafés, muitos com essa dupla função. (...) Nas aldeias e vilas menores, os grupos de leitura eram menos formais, mas não menos importantes.

Samuel Gompers, um dos fundadores da American Federation of Labor e seu presidente por muitos anos seguidos, relata em suas memórias a existência do hábito de leituras organizadas entre os trabalhadores charuteiros de Nova York, por volta de 1870: 
Havia também leituras que se faziam na fábrica enquanto se trabalhava. Era costume dos charuteiros organizar um fundo para a compra de jornais, revistas e livros e, enquanto os outros trabalhavam, um de nós era escolhido para ler, mais ou menos durante uma hora, ou talvez mais. Depois (...) tínhamos uma espécie de debate que chamávamos, naquele tempo, de "fórum trabalhista" e essa prática muito contribuía para desenvolver, entre nós, uma certa acuidade em assuntos econômicos de importância. (Gompers apud Rodrigues, 1974, p. 54)

A educação sempre mereceu atenção especial dos anarquistas, em parte porque sempre lhes pareceu ser essa uma das áreas em que poderiam dar início ao processo de transformação social, enquanto esperavam as transformações gerais da sociedade. Reconhecem, como fez William Godwin, quão poderoso instrumento a educação poderia ser nas mãos de governantes inteligentes e decididos. Reconhecem também até onde ela é capaz de estimular a livre conscientização, sem a qual é impossível esperar que ocorra qualquer mudança básica na sociedade. ${ }^{7}$

O movimento anarquista desenvolveu-se em torno de três grandes temas: a) o questionamento da ordem social existente; b) o projeto de uma nova ordem social; e c) o processo capaz de fundar essa nova ordem social. As atividades de natureza educacional promovidas pelo movimento, tanto no plano da teoria (a educação libertária) quanto no plano da prática (fundação e manutenção de escolas, centros de estudos e universidades populares), referem-se, sobretudo, a esse último grande tema. Em outras palavras, a educação ocupava uma importante posição estratégica no processo da revolução social, tal como a desejavam promover os anarquistas. A ligação entre a educação e o processo de mudança social foi claramente exposta por Malatesta (1981, p. 203207), para quem o essencial desse processo dependia da atuação harmônica de três forças: "a educação, a propaganda e a rebeliāo".

Há que se destacar a importância do pensamento de Fernand Pelloutier (1971), que, de 1892 a 1914, muito contribuiu para que progredisse a causa da formação operária específica no próprio movimento operário. O essencial da contribuição desse militante pode ser resumido em cinco premissas, a saber:

1) A necessidade, para os militantes, de não se contentarem com uma formação técnico-profissional. Ou seja, é indispensável que se juntem a essa formação conhecimentos econô- 
micos e sociais, bem como uma sólida formação geral. O que faz mais falta à classe operária é "a ciência da sua infelicidade".

2) A necessidade, para o movimento operário, de montar ele próprio os órgãos educativos: o serviço especializado das bolsas de trabalho. ${ }^{8}$

3) A confiança na capacidade da classe operária e na aptidão dos trabalhadores para criarem uma "nova cultura", novas "humanidades".

4) A "recusa da riqueza": isto é, a vontade de continuar a pertencer ao povo e de ficar a seu serviço. Para alcançar esse objetivo, não há nenhum meio melhor que o de continuar a ser trabalhador, ajudando "os camaradas a formarem-se" e auxiliando na adesão ao sindicato.

5) A consciência de Pelloutier em reconhecer que, no domínio da formação dos trabalhadores, ainda se está no princípio. Não há dúvida de que todos os esforços de formação "servem verdadeiramente à causa do movimento operário".

Dois elementos foram importantes nas diferentes elaborações teóricas relacionadas a uma "cultura de classe": a valorização do trabalho "produtivo", ou seja, do trabalho manual, do "produtor" que cria as riquezas do universo (expropriadas pelos burgueses); e a idéia de que, em oposição ao obscurantismo cultural e à irracionalidade da sociedade capitalista, seria possível a criação de um novo mundo, governado pelos próprios produtores e presidido pela razão. ${ }^{9}$

O próprio Marx, em 1868, reconhece que:

O setor mais culto da classe operária compreende que o futuro de sua classe e, portanto, da humanidade, depende da formação da classe operária que há de vir. (...) A sociedade não pode permitir que pais e patrōes empreguem, no trabalho, crianças e adolescentes, a menos que se combine este trabalho produtivo com a educação. Por educação entendemos três coisas: 1) Educação intelectual. 2) Educação corporal (...). 3) Educação tecnológica (...). Esta combinação de trabalho produtivo pago com a educação intelectual, os exercícios corporais e a formação politécnica elevará a classe operária acima dos níveis da classe burguesa e aristocrática. ${ }^{10}$

Para Marcel David, num país como a França até 1914, o "problema da formação operária ocupa um lugar relativamente secundá- 
rio na vida sindical" (David, 1974, p. 277). O estudo e a cultura não constituem ainda "centros de reflexão autônomos". São preocupações ocasionais que surgem por conta da formação técnico-profissional.

Mesmo nos congressos sindicais, as temáticas abordadas giravam em torno dos "cursos profissionais", acrescentando-se a esses cursos uma "parte sindical”, sem indicar com exatidão o conteúdo. Em 1902, por exemplo, cria-se uma comissão confederal de educação sindical com o objetivo principal de "formar rapazes e raparigas por meio de conferências, circulares, brochuras". Em 1908, tem-se a constituição das "Escolas Sindicais" para crianças.

A partir de 1919, nos congressos promovidos pelas centrais sindicais (Confédération Générale du Travail - CGT, fundada em 1895, e Confédération Française des Travailleurs Chrétiens - CFTC, fundada em 1919), o problema da formação aparece principalmente nos relatórios apresentados pelos militantes. Surgem ainda as "sessões confederais de estudos e práticas sindicais" e as escolas normais operárias - em duas ou três regióes de Lyon e Paris. Em 1932, a CGT cria o Centro Confederal de Educação Operária (CCEO), que dá origem, em Paris, a um Instituto Superior Operário e aos Colégios do Trabalho noutras regióes. É importante enfatizar que o CCEO goza de uma relativa autonomia estrutural em relação à CGT. O objetivo é dar uma formação que não seja apenas técnica, como na então União das Repúblicas Socialistas Soviéticas (URSS), nem essencialmente geral, como na Inglaterra e na Escandinávia, nem reservada aos funcionários, como na Bélgica. Desse modo, a formação deverá ser acessível aos militantes "e mesmo a qualquer aderente perante o qual se abra a perspectiva de uma vida militante" (David, 1974, p. 287).

Entre 1948 e 1950, cada central sindical coincidentemente estava preocupada com a instalação e normalização das suas estruturas educativas. Disso decorre

o fato de cada central sindical valorizar os problemas da formação pelo estudo, considerada como uma das duas ou três condições fundamentais para a existência de um sindicalismo forte. Em conseqüência, assiste-se ao acabamento da constituição dos dispositivos de formação. No plano nacional, são as três escolas centrais de Bierville para a CFTC, de Courcelles para a CGT, da Avenida do Maine, em Paris, para a FO [FORÇA OPERÁRIA]. Cada central define igualmente toda uma política educativa, com 
aspectos comuns a todas (...), mas também com aspectos particulares a cada uma. (David, 1974, p. 291)

Em 1956 foram criados os Institutos Universitários do Trabalho e, entre 1960 e 1961,

o movimento operário, ao mesmo tempo em que acentua o seu esforço de educação dos militantes, situa-o de maneira cada vez mais clara dentro de uma perspectiva cultural alargada. (...) Em resumo, as organizações sindicais estão de acordo em estar presentes nas instâncias que contribuem para a realização da política de desenvolvimento cultural. (David, 1974, p. 292-293)

É interessante notar que as experiências de educação em países como a França, a Bélgica, a Argentina e o Brasil, entre outros, apontam propostas e práticas de anarquistas, socialistas, comunistas e de diferentes grupos sindicais preocupados com a valorização do estudo e da cultura como uma das condições para a existência de um movimento operário forte. É importante também salientar que a formação sindical, além de adaptar-se às exigências e à estrutura de cada organização sindical, é em geral fortemente condicionada pela relação tradicionalmente instaurada entre os intelectuais e o país. Evidentemente isso depende dos diferentes graus de força e presença do sindicato entre os trabalhadores. ${ }^{11}$

Na consolidação da idéia de formação permanente, o movimento sindical, sobretudo quando se realizou o entrelaçamento entre movimento operário e movimentos de caráter intelectual, teve um papel proeminente. Nesse sentido, na França, teve um papel decisivo o movimento promovido por intelectuais e trabalhadores em 1968, que levou aos acordos de Grenelle entre governo e sindicatos, que, por sua vez, deram início à legislação sobre a formação permanente e a formação profissional contínua. Desse modo, os trabalhadores podiam gozar de licenças remuneradas de até seis meses por ano, a cargo do fundo para a formação. Além disso, a experiência de trabalho podia ser reconhecida como fator relevante para se ter acesso à universidade, mesmo não tendo obtido o diploma de segundo grau.

Entretanto, legislações e apoios não podem ser explicados simplesmente por uma espécie de colaboração e reformismo. Na realidade, a sensibilidade e o aguerrimento dos sindicatos e dos intelectuais envolvidos foram determinantes para experiências tão importantes. 
Em países como a Bélgica, a França, a Alemanha, a Grã-Bretanha e a Suécia, os trabalhadores gozam de licenças remuneradas, tuteladas pela lei, para participar de atividades de formação sindical. Em alguns, elas se aplicam a todos os trabalhadores envolvidos em tais atividades; em todos eles as licenças existem para quem desenvolve atividade sindical durante um período mais ou menos extenso, sendo usufruídas primeiramente pelos comitês de empresa; em alguns desses países, quem desempenha a militância sindical como formador tem possibilidade de gozar licenças ainda mais amplas. Nesses países, como formas de apoio à formação sindical, "existem contribuições específicas para a formação desenvolvida pelos sindicatos; em outros as formas de apoio são em geral para a educação permanente e para os adultos, nos quais entram também os centros de formação sindical (...)" (Memo, 1991, p. 8-9).

$\mathrm{Na}$ Inglaterra, a relação entre movimento sindical, universidade e escola pública tem uma tradição bem mais longa, iniciada com a instituição do Ruskin College em Oxford, em 1899 - conforme mencionado anteriormente -, com o apoio dos sindicatos, e que se amplia de maneira significativa depois de 1920, quando a "Universidade de Nottingham, em primeiro lugar, dá início a uma faculdade aberta, cujo objetivo não é o de conceder títulos de graduação, mas promover a educação permanente na sociedade. Em 1922, também em Nottingham, institui-se a primeira cadeira de educação de adultos" (Memo, 1991, p. 7).

É oportuno lembrar que E. P. Thompson, por quase duas décadas (entre 1948 e 1965), ocupou-se da educação de adultos no Departamento de Estudos Extracurriculares da Universidade de Leeds. Fundado em 1946, o departamento era parte da expansão da universidade inglesa no pós-guerra e seu chefe era o economista Sidney Raybould, além disso, mantinha um apoio ao bem-estar social e à extensão educacional, como uma ponte entre a universidade e os antigos compromissos com a Associação Educacional dos Trabalhadores (Workers' Education Association - WEA), desde 1903 empenhada em oferecer cursos de treinamento prático aos trabalhadores. ${ }^{12}$

Naquelas salas de aula, Thompson encontrava interlocução e estímulo entre homens e mulheres comuns (trabalhadores manuais, bancários, funcionários de escritório, profissionais de seguridade social e professores da rede de ensino não-universitária) durante os cur- 
sos de educação de adultos. "Quando falava com eles do mundo do trabalho", relembra o autor,

percebia uma tradição oral muito vivaz e um grande ceticismo com relação à história oficial. Com freqüência, esse ceticismo está bem fundamentado. Por exemplo, os livros dizem simplesmente que em tal ou qual ocasião foi aprovada uma série de leis sobre a jornada de trabalho. Porém, não contam como meninos eram escondidos em cestas erguidas até o teto quando da passagem dos inspetores. (Thompson, 1996, p. 409)

Dorothy Greenald e Peter Thornton, ${ }^{13}$

integrantes da primeira turma de Thompson em Cleckheaton, de 1948 a 1951, lembraram-se de que Edward fazia a história tornar-se viva para seus alunos, e mais particularmente "demonstrava que nossa formação não era motivo para envergonhar-se". "Isso realmente me fez mudar", disse Dorothy, em uma declaração que talvez seja o mais caro tributo a qualquer professor. (Palmer, 1996, p. 85-86)

De acordo com Bryan D. Palmer, Thompson considerava-se leal

à finalidade primeira da WEA: (...) oferecer acesso ao ensino superior àqueles que foram impedidos de tê-lo por circunstâncias materiais e a oportunidade conjunta de aprender e de trazer suas experiências para o ambiente da sala de aula. Não há dúvida de que Thompson recusou qualquer indício de paternalismo na experiência do aprendizado. Optou pela educação para adultos precisamente porque ela lhe oferecia a possibilidade, à maneira de Morris, de "formar socialistas" ao mesmo tempo que lhe abria novas perspectivas de aprendizado para si próprio: "Escolhi a educação para adultos porque me pareceu ser uma área em que aprenderia alguma coisa a respeito da Inglaterra industrial e ensinaria às pessoas que me ensinavam”. (Palmer, 1996, p. 82) ${ }^{14}$

\section{Educação operária em terras brasileiras}

No Brasil, a preocupação educacional no movimento operário-sindical inicia-se com as propostas educativas dos libertários, particularmente dos grupos anarco-sindicalistas, no período de 1902 a 1920. O projeto educativo dos libertários tinha três dimensões que se ligavam: a educação político-sindical, a educação escolar e as práticas culturais de massa. A educação político-sindical, ou seja, a educação para a transfor- 
mação revolucionária efetivava-se, por um lado, com o engajamento em movimentos e lutas de reivindicação, protesto e resistência e, de outro, com a divulgação dos ideais libertários em conferências, debates e estudos promovidos em sindicatos e centros de estudos. ${ }^{15}$ A educação escolar representava outra iniciativa importante dos anarquistas, que foi a criação das Escolas Modernas. Inspirados no ideário do pedagogo Francisco Ferrer, os libertários dirigem sua crítica contra o exercício do poder nas relações que se produzem em todos os espaços de sociabilidade: na escola, em casa, no trabalho, nos espaços de lazer. A escola libertária destinava-se a proporcionar aos filhos dos trabalhadores uma educação livre, racionalista e laica. ${ }^{16}$ Há que se ressaltar o fato de que a experiência curta da Universidade Popular, fundada em 20 de março de 1904 no Rio de Janeiro, diferentemente dos Centros de Estudos, não constituiu uma iniciativa exclusiva dos grupos anarquistas do movimento operário-sindical. Ela contou com o apoio de muitos literatos e intelectuais anarquistas, mas também fizeram parte do grupo que a articulou vários intelectuais socialistas. A Universidade Popular tinha como principais objetivos ministrar "o 'ensino superior positivo', científico e filosófico (...) ao proletariado. Mas não só isso, ela deveria também tornar-se um centro de lazer e cultura que congregasse os trabalhadores através de atividades libertárias e artísticas (...)" (Ghiraldelli Jr., 1987, p. 121). Por fim, as práticas no campo cultural e do lazer incluíam teatro, festivais de música e poesia e piqueniques promovidos pelos libertários nos bairros operários dos centros industrializados da época (Hardman, 2002 p. 39-113).

Sílvia Manfredi, em um texto fundamental sobre experiências e práticas de educação dos trabalhadores brasileiros, enfatiza sobretudo o "caráter globalizante" do projeto de educação dos libertários (aspectos culturais, educativos e libertários), que o distinguia "como um projeto de educação classista (...) voltado para a emancipação político-ideológica e cultural da classe operária”. Dessa forma, os libertários propuseram a construção de um "projeto educativo singular, próprio e autônomo" (Manfredi, 1996, p. 26).

De modo geral, entre as décadas de 1930 e 1960 podem-se agrupar em três tipos as práticas de formação sindical: as práticas avalizadas e incentivadas pelo Ministério do Trabalho; as práticas educativas dos próprios sindicatos e as de diferentes instituições - como partidos e organizações de esquerda, os chamados Centros de Educação Popular, as agências articuladas às classes dominantes, além da atuação da Igreja Católica e da Frente Nacional do Trabalho (FNT). ${ }^{17}$ 
É necessário destacar que, nesse período, a presença do Partido Comunista Brasileiro ( $\mathrm{PCB}$ ) no movimento operário-sindical é de fundamental relevância, considerando-se a importância conferida à formação político-partidária (formação de quadros). ${ }^{18}$ Nesse sentido, merece realce a experiência das escolas do РCB nos anos de 1950, no que tange à pedagogia comunista. Essa experiência se constitui na primeira iniciativa de educação política realizada no interior de um partido no Brasil e que atingiu uma certa amplitude. Ou seja, organizar escolas e cursos diferenciados para a formação político-ideológica dos seus militantes no Brasil — por exemplo, o curso "superior" denominado "Curso Stálin". É importante destacar ainda, entre outras coisas, a política cultural formulada e implementada de 1950 até 1956 e as ações e posturas dos militantes de base que atuavam nos bairros (nos Comitês Democráticos de Bairros), nas fábricas e no interior dos sindicatos, evidenciando que o $\mathrm{PCB}$ não constituía um "bloco monolítico", mas abrigava, isso sim, diferentes perspectivas pedagógicas. ${ }^{19}$

Mesmo que as Escolas do РСВ divulgassem um marxismo-leninismo de forma esquemática e padronizada, a experiência do PC, no que se refere às próprias escolas e à atuação tenaz dos militantes, sem dúvida alguma influenciou tanto conceitual como metodologicamente a atuação dos demais grupos de esquerda no âmbito da formação político-sindical do movimento operário-sindical nos anos subseqüentes.

No caso dos sindicatos, observa-se que em São Paulo os principais envolvidos com práticas de educação são os metalúrgicos da capital e de Santo André, e no Rio de Janeiro são os têxteis, os metalúrgicos e os bancários. ${ }^{20}$ É importante também salientar que, no período compreendido entre as décadas de 1970 e 1980, multiplicaram-se por todo o Brasil as experiências de formação em sindicatos de setores mais organizados e ativos na condução do movimento. Como no caso dos metalúrgicos de São Paulo (SP), de São Bernardo do Campo e Diadema (SP), de Santo André (SP), da Baixada Santista (Santos/SP), de João Monlevade e Betim (MG), dos bancários de São Paulo (SP), entre outros. Assim como o trabalho gerado pelas federações, confederações e mesmo associações independentes dos sindicatos.

Em 1980, por exemplo, o Departamento Intersindical de Estatística e Estudos Socioeconômicos (DIEESE) organizou o I Encontro de Educação em Sindicatos, que contou com a participação de oito entidades, dentre as quais estavam presentes o Sindicato dos Bancários do Rio de 
Janeiro e o Sindicato dos Metalúrgicos de São Bernardo. No resumo dos debates, muitos

companheiros (...) manifestaram a idéia de que, num curso de educação sindical, o trabalhador se conscientiza de que é "o produtor e o agente de transformações sociais”. (...) Constatamos que há grande interesse dos dirigentes em cursos de educação sindical. O Departamento Profissional dos Metalúrgicos tem desenvolvido estas atividades em vários estados do Brasil. Estão surgindo cada vez mais novos dirigentes, que precisam ampliar sua preparação, através dos cursos. "A vontade de aprender é muito grande", como relatou um dos companheiros. ${ }^{21}$

A experiência de formação situava-se, também, no campo dos Centros de Educação Popular. Merece registro tanto a Federação de Órgãos para Assistência Social e Educacional (FASE) como o Centro Ecumênico de Documentação e Informação (CEDI), que existiam desde os anos de 1960. Da mesma forma, no decorrer dos anos surgiram vários centros (em vários estados), com grande influência no meio pastoral, popular e sindical. Dentre eles, pode-se citar: o Centro de Educação Popular do Instituto Sedes Sapientae (CEPIS); o 13 de Maio - Núcleo de Educação Popular -, ambos em São Paulo; o Centro de Assessoria Multiprofissional, no Rio Grande do Sul; e o Centro de Ação Comunitária (CEDAC), no Rio de Janeiro.

As atividades de formação sindical são espaços privilegiados de "troca de experiências"; são também espaços para se elaborar em conjunto uma nova forma de pensar (organizar idéias, criar novos conceitos, analisar conhecimentos já teorizados etc.) e uma nova forma de planejar a ação sindical.

Em agosto de 1983 foi fundada a Central Única dos Trabalhadores (CUT), que previa já no seu estatuto provisório a criação de uma Secretaria de Formação, Educação e Cultura. Atualmente, a CUT conta com sete escolas sindicais. A Central Geral dos Trabalhadores (CGT), criada em 1986, também estruturou o seu projeto de educação um ano após sua fundação. Do mesmo modo, nos Anais do I Congresso da Força Sindical, em março de 1991 — época de sua fundação —, já se previa a criação de uma Escola Nacional de Formação, um Instituto de Estudos e Pesquisas e um Departamento (ou Secretaria) Nacional de Formação. ${ }^{22}$ Em nenhum dos casos existe legislação governamental sobre formação - a exemplo de países como Bélgica, França, Alemanha, Grã-Bretanha e Suécia. 
Apesar da ação dos governos conservadores ao longo da década de 1980, que reduziu os fundos à disposição da formação sindical, hoje, na Grã-Bretanha,

382 são os tutores contratados por universidades e colleges que dedicam a maior parte do tempo aos cursos sindicais: tanto nos institutos superiores, técnicos e políticos, onde se desenvolvem os cursos com licença remunerada para os representantes de departamentos e os funcionários da segurança nos locais de trabalho, (...) como nas universidades, onde se desenvolvem outras atividades em colaboração com o sindicato. (Memo, 1991, p. 7)

A necessidade de formação não diminui com o aumento do nível de instrução, mas, ao contrário, cresce. De acordo com Roger Cantigneau, responsável pela formação sindical da Confederação dos Sindicatos Cristãos (CSC) belga, "com o aumento dos níveis de instrução hoje, os trabalhadores não aceitam mais seguir as indicações dos grupos dirigentes do sindicato sem discutir a fundo as razões; é, além disso, impensável um maior papel dos organismos de representação das empresas sem fornecer a eles os instrumentos culturais e informativos necessários”. Na Bélgica, tanto a Confederação dos Sindicatos Cristãos quanto a Federação Geral dos Trabalhadores da Bélgica (FGTB) estão empenhadas em atividades culturais, formativas e de pesquisa, e é interessante observar que, sozinhas, as duas entidades representam mais de $90 \%$ dos trabalhadores (Memo, 1991, p. 10).

Segundo Marcel David, o percurso do movimento sindical vai em direção à constatação

de que a prática é insuficiente como meio de formação. A prática, naturalmente, é indispensável, e sob as suas várias formas, mas quando não é completada pelo estudo torna-se insuficiente. (...) Daí o facto de cada central sindical valorizar os problemas da formação pelo estudo, considerada como uma das duas ou três condições fundamentais para a existência de um sindicalismo forte. (...) Durante a maior parte da sua história, foi graças aos seus intelectuais que o movimento operário conseguiu dar o melhor da sua contribuição específica. (...) Por outro lado, também já não é só devido aos intelectuais, mas também graças à contribuição dos trabalhadores militantes, que a reflexão cultural, liberta dos exageros do "obreirismo", se revela fecunda. (David, 1974, p. 290-291 e 294)

Marcel David não é um personagem atípico empenhado em atividades de formação operária dentro da universidade, na verdade, existe 
uma vertente de intelectuais franceses que começa com o Iluminismo, mas é testemunhada no século XX, seja por laicos como Sartre, seja por católicos como Maritain. Em geral, em vários países da Europa, por exemplo, já a partir do século XIX existe uma relação de cooperação entre movimento sindical e universidade.

É interessante ressaltar como Marcel David procura situar o tema da educação operária, resgatando o significado da luta de classes. Ele sustenta a idéia de uma marche em avant do gênero humano, "de progressão positiva, de melhoramentos em vários sentidos, não como necessidade condicionando a história numa via absoluta e determinista, mas como dinâmica com resultados múltiplos" (David, 1967, p. 137). Além disso, o autor destaca algo que parece uma reedição do velho aforismo de Marx: "o progresso abrangente, a possibilidade de emancipação crescente", isto é, "a civilização é de responsabilidade dos próprios trabalhadores" (idem, ibid.). Contra a fragmentação e atomização social impostas contra o individualismo auto-suficiente e desagregador, destaca-se o movimento associativo de entidades comprometidas com as lutas sociais e com o estudo. Uma "forma de valorizar a existência humana, de dar à humanidade a chance de não mais restringir a fruição do progresso a um círculo estreito de privilegiados, de permitir a promoção individual em dimensóes cada vez mais amplas que apenas o coletivo permite" (idem, ibid., p. 137-138).

Guido Memo, em um trabalho mais recente, afirma que

a formação não pode seguir uma postura de caráter 'militar', que impõe métodos e conteúdos decididos em outro lugar e do alto, nem pode ser simplesmente concebida como uma transmissão de saberes no âmbito das disciplinas tradicionais. É preciso incentivar processos de autoformação, de reflexão crítica e criativa: a partir das experiências desenvolvidas por cada grupo e por projetos de intervenção. (...) A formação deve estimular a capacidade de empreendimento social, que coopera, mas se necessário afronta também, com instituiçôes e sujeitos que operam no território. É necessária uma formação de base, difusa, e de 'quadros', que deve ser tanto formação técnica, para criar capacidades concretas de intervenção no próprio setor, como formação política. Com a finalidade portanto de gerar conhecimento (...) A formação é um recurso para os grupos e para as organizações, mas é preciso afirmar que é antes de tudo um direito de cada pessoa, para uma participação crítica e consciente e para um crescimento e adequação das próprias capacidades profissionais (...). (Memo, 1991, p. 14-15) 
A formação sindical se preocupa com questôes práticas do cotidiano do trabalhador e do movimento sindical. Torna-se um espaço em que os agentes do movimento sindical vão pensar a sua prática, vão repensar as "teorias" do próprio movimento e vão difundir as novas descobertas. Dessa forma, o movimento operário - em meio à crise do sindicalismo em âmbito mundial - tem se defrontado com os mais diversos temas, que vão desde a questão do planejamento sindical, da negociação coletiva, da proposta de contrato coletivo, da organização por local de trabalho, da formação profissional em face das questôes postas pela reestruturação produtiva, do meio ambiente, da globalização, das relações de gênero, da questão racial, da questão do jovem, até a questão das crianças de rua, e assim por diante. ${ }^{23}$ Neste sentido, a formação sindical é um importante meio de organizar a classe trabalhadora, assim como de incentivar a "educação dos sentidos" dos trabalhadores.

\section{Recebido em junho de 2003 e aprovado em junho de 2004.}

\section{Notas}

1. Cf. Marx, "Manuscritos econômicos e filosóficos”, em Fromm (1979, p. 83-170).

2. Ver ainda Marx (1982, v. 1, p. 300).

3. Vale ressaltar que Marx reconheceu que a possibilidade de aumento de salário real significaria para os operários, sob certas circunstâncias, ter uma melhoria nas suas condições de vida, adquirir uma maior quantidade de bens de consumo, usufruir as benesses da civilização burguesa mesmo sob o capitalismo. Nos Grundrisse, ele argumenta que, em épocas de bons negócios, os operários poderiam tomar parte "em desfrutes superiores inclusive espirituais - a agitação em favor de seus próprios interesses, ler jornais, assistir a conferências, educar os filhos, formar seus gostos etc." (Marx, 1986, p. 230).

4. Sobre o Ruskin College e o movimento inglês de instrução proletária, cf. Holford (1994).

5. Sobre as sociedades de educação operária desde 1854 na Alemanha, ver Lefranc (1974, p. $15-20)$.

6. Em fins de 1846, Karl Marx dirige o Comitê de Correspondência Comunista em Bruxelas e faz conferências econômicas numa sociedade de educação operária; cf. Fougeyrollas (1989, p. 23).

7. Cf. "Os males de um ensino nacional" e "Educação pela vontade", de William Godwin, em Woodcock (1981, p. 246-253).

8. A primeira das "bolsas de trabalho" foi criada em Paris, em 1887; ver a esse respeito Pelloutier (1971). No caso do movimento operário brasileiro, conferir Simão (1981, p. 154).

9. O mesmo tipo de preocupação intelectual e cultural existiu também no Brasil - mais precisamente em São Paulo e no Rio de Janeiro - com os clubes de debates ou Centros de 
Estudos Sociais, animados por trabalhadores emigrados, anarquistas na maioria das vezes; cf. Dias (1977).

10. Marx, "Instruções aos delegados do conselho central provisório, AIT, 1868", em Marx \& Engels (1992, p. 60).

11. Sobre formação operária e/ou sindical, ver David (Org.) (1957) e Memo (Org.) (1991).

12. Maiores detalhes da experiência de E. P. Thompson como professor em "Edward Thompson as a teacher: Yorkshire and Warwick", de Peter Searby, R. Malcolmson e J. Rule, In: Rule \& Malcolmson (Org.) (1993, p. 1-23).

13. O livro de Thompson, A formação da classe operária Inglesa, foi dedicado a ela e a Joseph Greenald. A esse respeito, ver Thompson (1966).

14. Segundo o estudo de Maria Elisa Cevasco, tanto E.P. Thompson como Raymond Williams "foram membros ativos da WEA (...). Esse tipo de trabalho representava, na avaliação de Williams, uma forma de atividade social e cultural que lhes possibilitava reunir o que, em suas vidas pessoais, tinha sido apartado: o valor de um conhecimento mais avançado e a privação contínua desse benefício em sua classe de origem ou afiliação" (Cevasco, 2001, p. 123).

15. Ver, sobre o tema, Ghiraldelli Jr. (1987, p. 117-120).

16. Sobre a educação anarquista e as Escolas Modernas, ver: Hardman (2002, p. 76-94).

17. Cf., entre outros, Paranhos (1999, p. 189-199).

18. A preocupação com a formação político-partidária, que compreendia a formação de quadros como tarefa básica do PCB, é fruto de uma orientação internacional que regia os PCs. Ver Tartakowski (1975, p. 79-108).

19. Ver, entre outros, Manfredi (1996, p. 45-87) e Santana (2001).

20. Cf. Manfredi (op. cit., p. 84); Camacho (1999) e Mattos (1998, p. 121-133).

21. DIEESE (1981, p. 4-5). Ver também Chaia (1992, p. 180-181).

22. Sobre formação em sindicatos e nas centrais sindicais, ver, entre outros, Tumolo (1998) e Paranhos (2002).

23. Sobre os desafios e perspectivas atuais do sindicalismo, ver especialmente o livro organizado por Rodrigues (1999).

\section{Referências bibliográficas}

BOTTOMORE, T. (Ed.). Dicionário do pensamento marxista. Rio de Janeiro: J. Zahar, 1988.

CACERES, B. Histoire de l'education populaire. Paris: Seuil, 1997.

CAMACHO, T. Cultura dos trabalhadores e crise politica: estudo sobre o Centro Popular de Cultura do Sindicato dos Metalúrgicos de Santo André. Santo André: Secretaria de Cultura, Esporte e Lazer, 1999.

Educ. Soc., Campinas, vol. 26, n. 90, p. 266-288, Jan./Abr. 2005

Disponível em <http://www.cedes.unicamp.br> 
CEVASCO, M.E. Para ler Raymond Williams. São Paulo: Paz \& Terra, 2001.

CHAIA, M.W. Intelectuais e sindicalistas: a experiência do DIEESE. 1955-1990. Ibitinga: Humanidades, 1992.

DAVID, M. (Org.). Pour un bilan de la formation ouvrière. Paris: Dalloz, 1957.

DAVID, M. Les travailleurs et le sens de leur histoire. Paris: Cujas, 1967.

DAVID, M. Formação operária e pensamento operário sobre a cultura em França a partir de meados do século XIX. In: BERGERON, L. (Org.). Niveis de cultura e grupos sociais. Lisboa: Cosmos, 1974.

DEPARTAMENTO INTERSINDICAL DE ESTATISTICA E ESTUDOS SOCIOECONOMICOS (DIEESE). Pesquisa sobre a situação da educação sindical no Brasil. 1981. (datilografado).

DIAS, E. História das lutas sociais no Brasil. 2. ed. São Paulo: AlfaÔmega, 1977.

FOUGEYROLlAS, P. Marx. São Paulo: Ática, 1989.

GHIRALDELLI JUNIOR, P. Educação e movimento operário. São Paulo: Cortez; Campinas: Autores Associados, 1987.

HARDMAN, F.F. Nem pátria, nem patrão!: memória operária, cultura e literatura no Brasil. 3. ed. rev. e ampl. São Paulo: UNESP, 2002.

HOLFORD, J. Union education in Britain: a tuc activity. Nottingham: University of Nottingham; Department of Adult Education, 1994.

LEFRANC, G. O sindicalismo no mundo. Braga: Europa-América, 1974.

MALATESTA, E. Sindicalismo: a crítica de um anarquista. In: WoodCOCK, G. (Org.). Os grandes escritos anarquistas. 2. ed. Porto Alegre: L\&PM, 1981. p. 203-207.

MANFREDI, S.M. Formação sindical no Brasil: história de uma prática cultural. São Paulo: Escrituras, 1996. 
MARX, K. Manuscritos econômicos e filosóficos. In: Fromm, E. Conceito marxista do homem. 7. ed. Rio de Janeiro: Zahar, 1979.

MARX, K. O capital: crítica da economia política. 8. ed. São Paulo: Difel, 1982. Livro 1, v. 1 e 2.

MARX, K. Elementos fundamentales para la critica de la economía política (Grundrisse) 1857-1858. 14. ed. México: Siglo Veintiuno, 1986.

MARX, K. Instruções aos delegados do Conselho Central Provisório, AIT, 1868. In: MarX, K.; Engels, F. Textos sobre educação e ensino. 2. ed. São Paulo: Moraes, 1992.

MATTOS, M.B. Novos e velhos sindicalismos: Rio de Janeiro (1955/ 1988). Rio de Janeiro: Vício de Leitura, 1998.

MEMO, G. (Org.). Cultura e democrazia sindacale in Europa: formazione e ricerca sindacale in sei paesi europei. Roma: Centro di Studi e Iniziative per la Riforma dello Stato, 1991. (digitado).

MUCCHIELLI, R. A formação de adultos. São Paulo: Martins Fontes, 1980.

PALMER, B.D. E. P. Thompson: objeçōes e oposições. Rio de Janeiro: Paz \& Terra, 1996.

PARANHOS, A. O roubo da fala: origens da ideologia do trabalhismo no Brasil. São Paulo: Boitempo, 1999.

PARANHOS, K.R. Mentes que brilham: sindicalismo e práticas culturais dos metalúrgicos de São Bernardo. 2002. Tese (Doutorado) - Instituto de Filosofia e Ciências Humanas, Universidade Estadual de Campinas, Campinas.

PELLOUTIER, F. Histoire des bourses du travail. Paris: Gordon \& Breach, 1971.

RODRIGUES, I.J. (Org.). O novo sindicalismo: vinte anos depois. Petrópolis: Vozes, 1999.

RODRIGUES, L.M. Trabalhadores, sindicatos e industrialização. São Paulo: Brasiliense, 1974. 
SANTANA, M.A. Homens partidos: comunistas e sindicatos no Brasil. São Paulo: Boitempo; Rio de Janeiro: Universidade do Rio de Janeiro, 2001.

SEARBY, P.; MALCOLMSON, R.; RULE, J. Edward Thompson as a teacher: Yorkshire and Warwick. In: Rule, J.; Malcolmson, R. (Org.). Protest and survival: essays for E. P. Thompson. Londres: The Merlin, 1993.

SIMÃO, A. Sindicato e Estado: suas relações na formação do proletariado de São Paulo. São Paulo: Ática, 1981.

TARTAKOWSKI, D. Un instrument de culture politique: les premieres ecoles centrales du parti communiste français. Le Mouvement Social, Paris, n. 91, p. 79-108, 1975.

THOMPSON, E.P. The making of the English working class. New York: Vintage Books, 1966.

THOMPSON, E.P. A formação da classe operária inglesa. Rio De Janeiro: Paz \& Terra, 1987. v.3.

THOMPSON, E.P. Intervista de E.P. Thompson. Quaderni Storici, Roma, n. 92, p. 405-427, 1996.

TUMOLO, P.S. A politica nacional de formação sindical da Central Única dos Trabalhadores diante do novo padrão de acumulação de capital. 1998. Tese (Doutorado) - Pontifícia Universidade Católica de São Paulo, São Paulo.

WOODCOCK, G. (Org.). Os grandes escritos anarquistas. 2. ed. Porto Alegre: L\&PM, 1981. 